\title{
Psychiatric Morbidity and Social Capital in Rural Communities of the Greek North Aegean islands
}

\begin{abstract}
Which facets of social capital affect mental health in rural settings? This study explores the association between different aspects of social capital and psychiatric morbidity in rural communities of the Greek North Aegean islands. A large number of individual and community characteristics which may influence psychiatric morbidity are concurrently examined in multilevel models to account for the clustering of individuals within rural settings. The current findings indicate that psychiatric morbidity is to a large extent clustered within rural communities. Individuals' perceived divisions in the community, i.e., political party preference, landholdings etc., low social support networks and lack of perceived solidarity are associated with psychiatric morbidity according to theoretical expectation. At the community level this risk is lower in villages with over 250 residents, where there are youth clubs or a common threat, for instance, property crime.
\end{abstract}

Keywords: mental health, social capital, multilevel logit models, rural communities, Greece. 


\section{INTRODUCTION}

Over the last decade there has been a daunting research interest in the investigation of the effects of social capital on health, especially, in the fields of socio-epidemiology and public health (Szreter \& Woolcock, 2004). This interest signifies an epistemological move from the study of socio-demographic variables to the study of social contextual factors as determinants of health. The concept of social capital arguably provides both a theoretical and methodological framework for capturing a contextual perspective in this line of investigation (Lochner, Kawachi \& Kennedy, 1999). While several definitions of social capital exist, most seem to agree that social capital is a multidimensional concept comprising norms, relationships and networks that facilitate cooperation and collective action (Woolcock \& Narayan, 2000).

The research however into the association between social capital and mental health is limited. De Silva (2006) conducted a systematic review of twenty-eight quantitative studies examining the association between social capital and common mental disorders (CMDs) by placing emphasis on methodology. De Silva's review reveals a diverse collection of studies with varying ways of conceptualizing social capital, levels of measurement (individual or ecological), mental health outcomes and methododology including study design, sample size, setting (urban or rural) and statistical techniques. She noted that, despite the growing sophistication of data analysis through the use of multi-level modeling, the relationship between social capital and mental health is rather complex and 'varies by setting, aspect of social capital and mental health outcome' (De Silva, 2006, p. 54). 
Evidence by McKenzie \& Harpham (2006) indicates that different facets of social capital have diverse effects on mental health depending on the socio-economic population group examined. They concluded that, although in some circumstances aspects of social capital may impact mental health, the interplay between wider social problems, such as poverty, gender inequality, unemployment, socio-political deprivation and individual risk factors (e.g. school drop out) are more powerful predictors of negative mental health. Research in social capital suggests that 'vertical' social capital is likely to affect mental health through supporting the linkages of disempowered population groups with the wider structures of resources irrespectively of contexts examined. The importance of 'bridging' social capital and individual factors, such as relative deprivation, has also been evidenced by Whitley (2006) who reported high levels of CMD's in an urban community in London despite the presence of rich neighbourhood trust and social activity.

In what ways social capital and mental health interact? Explicit hypotheses about mechanisms linking social capital to mental health have not yet been developed systematically. The long tradition of theoretical and empirical work on the relationship between social ties, social integration and health conducted throughout the 1970s and 1980s (Cohen \& Wills, 1985) may offer insights about the ways that social capital influences mental health. Berkman, Glass, Brissette \& Seeman (2000) proposed a conceptual model that links social network to health by integrating macro-level phenomena, such as wider social and cultural forces, with micro-level psychobiological processes. They argued that social networks function as mediating structures between macro- socio-structural conditions and micro-scale forms of behaviours. Social ties and 
networks are expected to provide opportunities for social support, social influence, social engagement, intimate contact and access to resources. The mechanisms by which a range of resources impact health include: 1) diffusion of norms which relate to health behaviours, 2) psychological processes including self-efficacy, self-worth and security, and 3) neurobiological states. The current study is partly motivated by Berkman and colleagues' (2000) theoretical proposition of the ways social capital and mental health may interplay.

This paper considers the relationship between perceptions of community life, measures of social capital and individual mental health in rural communities of the North Aegean Sea, Greece. The region includes three prefectures, Lesvos, Samos and Chios and consists of nine small-, large- and medium-size islands, spread in the north eastern part of the Aegean Sea. The choice of rural settings is important for two reasons: first, little research has been directed towards examining the associations between social capital and mental health in such contexts (De Silva, 2006) and, second, a critique to the notion of social capital includes issues of cultural dissonance by rural communities (Forbes \& Wainwright, 2001). Therefore, this research provides an opportunity to examine the link between social capital and mental health within socio-cultural environments other than urban Anglo-Saxon settings.

Mental health is measured via the revised Clinical Interview Schedule (CIS-R) which is a structured interview about the prevalence of psychiatric disorders (Lewis, Pelosi, Araya, \& Dunn, 1992). Social capital measures draw on Putnam's conceptualization (1993) as well as on the model proposed by Lochner et al. (1999). Putnam defines social capital as civic participation and norms of trust and reciprocity. Along the same lines, 
Lochner et al. (1999) identify cohesion, collective efficacy, psychological sense of community and community competence as key dimensions of social capital.

The current study investigates a twofold research question:

Which facets of social capital, if any, affect psychiatric morbidity in rural settings taking into account other individual and community attributes and the clustering of individuals within communities?

To this end empirical investigation via multilevel logit model of a unique data set from Greece is employed. The statistical model is appropriate for examining binary health outcomes for nested units of analysis (for an overview of the uses of multilevel models in health studies see, for instance, McKeehan, 2000). A description of the data set and the research instruments employed in this analysis follow (Sections 2 and 3). Thereafter the multilevel logit model is formally given and preliminary associations between psychiatric morbidity and various constructs of social capital are discussed. The main results of this study are presented in the sixth section while a discussion of the findings in light of the previous literature and how they may inform theory and future research concludes the paper.

\section{DATA}

The data for this work come from a large-scale cross-sectional survey on mental health and experiences and perceptions of community social life (Zissi, Tseloni, Skapinakis, Savvidou, \& Chiou, 2010). Community representatives and a randomly selected sample of residents in rural communities of the North Aegean islands participated in the survey which consisted of four modules: two qualitative and two sets 
of structured interviews. The current work employs quantitative data from the modules of structured interviews, i.e., the Household Questionnaire and the Community Profile.

The Household Questionnaire module was given to representatives of randomly selected households via stratified sampling as follows. First, all small rural communities of the region, whereby their population is under 2,000 inhabitants and at least $33 \%$ are farmers, were selected totalling 89 such areas. Second, a random sample of households from each rural community was selected with constant selection probability across communities from two mutually exclusive registers, namely the electoral register and the register of residents without electoral rights. Thus the total number of selected households is 428 . The household representative was, finally, selected on the basis of the adult household member with birth date nearest to the interview date according to standard survey practice (Hales, Henderson, Collins \& Becher, 2000; Kalton 1983). Household representatives were face-to-face interviewed by trained male and female social researchers. The fieldwork was undertaken in the summer of 2004 with average interview duration 45 minutes. This module includes questions on mental health, social capital and a wealth of demographic and socio-economic individual and household attributes, such as age, gender, occupation, schooling, household structure and affluence, which offer the study's level 1 or individual level covariates.

Additional face-to-face structured interviews with one key informant from each community $(\mathrm{n}=89)$ - most often a community councillor, priest or teacher - were conducted for gaining further insights of the community context in which the participants live. These interviews are based on the World Bank Community Profile (Grootaert \& van Bastelaer, 2002) which surveys a wide range of features of local environments (see the 
respective later sub-section) and provide the level 2 or community level covariates of this study in clear distinction from the Household Questionnaire module variables mentioned in the previous paragraph. Thus individual and community information and the respective data are independent from a statistical viewpoint.

The available data set entails a natural hierarchy of individuals nested within communities with variables available at each level for investigating the association between social capital and mental health. In particular, the study combines individuals' mental health, social capital, demographic and socio-economic characteristics with the communities' socio-demographic profile, infrastructure, resources, collective organizations and mobilization.

\section{RESEARCH INSTRUMENTS}

\section{Mental health}

Mental health is measured via the Revised Clinical Interview Schedule (CIS-R) a fully structured psychiatric interview designed to be used by trained lay interviewers (Lewis et al., 1992). The CIS-R was the main instrument used in the national psychiatric morbidity surveys in the UK (Jenkins, Bebbington, Brugha, Farrell, Gill, Lewis et al., 1997) and has been used in several other similar surveys around the world Araya, Rojas, Fritsch, Acuña \& Lewis, 2001). The CIS-R assesses the presence and severity of 14 different common psychological symptoms (psychosomatic symptoms, fatigue, concentration /forgetfulness, sleep problems, irritability, worry about physical health, depression, depressive ideas, worry, anxiety, phobias, panic, compulsions and obsessions). Two screening questions in each section ask about the presence of the symptom during the 
past month and then there is a more detailed assessment of the presence, frequency, duration, and severity of the symptom during the past seven days. Each symptom section is scored from 0 to 4 (except depressive ideas from 0 to 5) and a score of 2 or more denotes a clinically significant symptom (Lewis et al., 1992). Additional questions enable the application of the ICD-10 research diagnostic criteria using specially developed computerized algorithms. In addition, the distribution of total CIS-R score gives an indication of the severity of symptoms in a dimensional way.

The Greek version of the CIS-R was translated and back-translated using the procedure recommended by the World Health Organization (http://www.who.int/substance_abuse/research_tools/translation/en/index.html). Male and female interviewers were trained in the use of the CIS-R. The vast majority of respondents reported low or no psychiatric morbidity rendering the respective distribution highly skewed. A score of 12 (the current sample's upper quartile) or higher was used in this study to denote clinically significant psychiatric morbidity which was observed in $14.2 \%$ of respondents.

\section{Social Capital}

The structured interviews to the selected household members and each community representative focus on capturing cognitive and structural social capital dimensions. Structural social capital examines aspects of facilities, services and organizations which have been identified as characteristics crucial for the formation and development of social support (Cattell, 2001). The cognitive dimension includes both attitudinal and 
behavioural items. This sub-section describes the study's social capital measures at the individual level while the community profile follows in the sub-section after next.

Four key aspects of social capital with regards to individuals are examined: 1) social engagement, social networks and support, 2) collective efficacy, 3) trust and social cohesion and 4) sense of community. The majority of questions were sourced from the Social Capital Assessment Tool which is developed by the World Bank (Grootaert \& van Bastelaer, 2002) and adapted by the research team while additional sources are explicitly mentioned. All social capital measures except the number of perceived differences and friends are dichotomous in this study.

Engagement which refers to participation or involvement of each family member in local formal or informal groups was culturally alien to the respondents of this study and therefore it will not be examined further. The respective social networks and social support measures are:

- The number of close friends that the respondent can rely on or confine in. This is a three category nominal variable: none (34.9\%), one to three (49.5\%) and four or more $(15.6 \%)$ friends;

○ The number of friends to borrow money from indicating none (34.9\%), one to three $(44.8 \%)$ and four or more $(20.3 \%)$ friends; and

- Mutual aid or perceived solidarity which refers to helping the community in case of an emergency, i.e., whether the majority of the rural community's residents would join forces to address a common disaster (46.5\%).

Collective efficacy is measured by two items: 
○ Collective mobilisation or non-formal social participation, i.e., whether the majority would be involved in organizing a festival or fair in the village (45.0\%); and

- Willingness to invest both money and time (formal social participation) for a public good, such as the construction of a playground, in the village $(61.9 \%)$.

The Social Cohesion Scale (Sampson, Raundenbush, \& Earls, 1997) measures perceptions of shared values or differences and trust. Respondents were asked to indicate the extent to which they agree with five statements, using the 5-point Likert scale. The index was constructed by the following statements: 'People in this village can be trusted', 'This is a close-knit village', 'People around here are willing to help their neighbours', 'People in this village generally don't get along with each other', and 'People in this village do not share the same values'. The internal reliability of this scale was assessed by Cronbach's $\alpha$ which was equal to 0.762 . Low social cohesion $(45.5 \%)$ is implicated by values less than 2.60 of the raw scale. Additional social cohesion indicators include:

- Individual perceived differences in political party preference (45.3\%), landholdings $(24.3 \%)$ and mentality $(21.7 \%)$; and

$\bigcirc$ The total number of perceived differences which is an aggregate count adding gender, nationality, inter-generational, length of residence, educational level and wealth to the above differences $($ mean $=1.67$, standard deviation $=1.90$, range $=0-9)$.

The extend of trust in institutions and public services is captured by institutional trust to any of the following bodies: church, police, local authority, members of parliament, government, municipality or regional government and health services $(52.6 \%)$.

Sense of community captures satisfaction with and belongingness in the community. In the current study it is called attachment and refers to being happy or very 
happy in the village and perceiving it as a large family in which the respondent belongs $(50.7 \%)$.

\section{Demographic and Socio-Economic Characteristics}

A large number of individual, household and community characteristics which may be associated with mental health are examined in this study. These include sociodemographic attributes (age, sex, nationality, household composition, education, employment), indicators of affluence (income, home, car and pick-up trucks ownership) and residential stability of the individual respondents and their households.

\section{Community Profile}

The Community Profile (Grootaert \& van Bastelaer, 2002) includes: (a) general community characteristics (e.g. population size, principal economic activities, availability of employment, quality of housing, quality of roads); (b) principal services (e.g. availability and quality of electrical service, public lighting, drinking water, home telephone service, public telephones, sewage, waste collection, transportation); (c) recreation facilities, labour migration, education structures, environmental issues, community support (e.g. number of organizations existing in the community); and (d) prevalence of collective mobilization to address a local problem with identification of local social problems. Additional subjective perceptions of the community representatives on issues related to quality of life and levels of trust in their community were gauged. 
Examples of the contextual attributes and relevant perceptions of this study follow. These are population size; public resources and facilities, such as primary schools (55.1\%), internet access (57.3\%), public market (66.3\%), PTA's (42.7\%) or other clubs; quality of life (reported as good by 59.6\% of community representatives) and other social features, such as (relative (19.1\%)) trust (58.4\%) and community mobilisation (31.5\%); perceptions about the economy, i.e., improved employment prospects (27\%); and social problems prevalence, such as crime (16.9\%), drug (14.6\%) and alcohol abuse (21.3\%).

Summary statistics of all individual and community characteristics together with the key community informants' subjective perceptions which are employed in the current work are given in Table 1. The number of cases with valid responses across all sample characteristics for the later statistical modelling is 424 .

< Insert Table 1 about here>

\section{STATISTICAL MODEL}

The multilevel logit specification is employed to examine predictors of psychiatric morbidity, including social capital. The model accounts for the clustering of individuals within communities and estimates any between communities unexplained heterogeneity for binary observed outcomes (Goldstein, 1995; Snijders \& Bosker, 1999). Allowing for extra-binomial variance any divergence of the between individuals variation from the logistic distribution is also estimated.

Let $\pi_{i j}$ be the expected probability of psychiatric morbidity.

$\pi_{i j}=\left\{1+\exp \left[-\left(X_{i j} \beta+u_{0 j}\right)\right]\right\}^{-1} \quad i=1, \ldots, n_{j}, j=1, \ldots, 89$

$E\left(u_{0 j}\right)=0$

$\operatorname{Var}\left(u_{0 j}\right)=\sigma^{2}{ }_{u 0}$ 
where $u_{0 j}$ is the community-level error term associated with the intercept; $X_{i j}$ is a row vector of the set of $P$ covariates for the $i j$-th individual in the $j$-th community including the intercept; and $\beta_{p}$ is a vector of fixed coefficients including the fixed part of the intercept $\left(\beta_{0}\right)$. Since the probability distribution for the observed probability of psychiatric morbidity, $Y_{i j}$ for the $i j$-th individual, follows the logistic distribution the between individuals (level one) residuals, $e_{i j}$, have variance equal to $\frac{\pi^{2}}{3}=3.29$. In our estimated models below (see Tables 2 to 4 ) $\sigma_{e}^{2}$ is estimated to test for any extra-binomial variation which has a multiplicative effect to the standard logistic variance, i.e., $3.29 \sigma_{e}^{2}$.

Two derivative statistics which are formally introduced in this section are instrumental for disentangling the individual and community influences on psychiatric morbidity. The first is the so called intra-class correlation, ICC (Snijders \& Bosker, 1999) which depicts intra-community correlation. It gives the correlation of the probability of psychiatric morbidity between two randomly selected individuals residing in the same randomly chosen community (Snijders \& Bosker, 1999; Goldstein, 1995) and implies persistent community unexplained heterogeneity. In plain English it estimates how much psychiatric morbidity is clustered within communities. Formally the ICC is calculated as

$$
\rho=\sigma_{u 0}^{2}\left(\sigma_{u 0}^{2}+\frac{\pi^{2}}{3}\right)
$$

and allowing here for extra-binomial variation as

$$
\rho=\sigma_{u d}^{2}\left(\sigma_{u 0}^{2}+3.29 \sigma_{e}^{2}\right)
$$

The second instrumental statistic for disentangling community and individual influences on psychiatric morbidity is the proportion of explained variance by the 
independent variables of the estimated multilevel logistic models which is denoted as $R_{\text {dicho }}^{2}($ Snijders \& Bosker, 1999).

$$
\boldsymbol{R}_{\text {dicho }}^{2}=\frac{\sigma_{P}^{2}}{\sigma_{P}^{2}+\sigma_{u 0}^{2}+3.29 \sigma_{e}^{2}}
$$

where $\sigma_{P}^{2}$ is the variance of the linear predictor for an unobservable variable which generates the dichotomous outcome of psychiatric morbidity via a threshold process (Snijders \& Bosker, 1999); $\sigma_{u 0}^{2}$ and $3.29 \sigma_{e}^{2}$ have been defined above. Since most explanatory variables are categorical the linear predictor and therefore its variance, $\sigma_{P}^{2}$, and the resulting $R_{\text {dicho }}^{2}$ are a function of the attributes included in each estimated model. Therefore different predictors would give a slightly different value of the proportion of explained variance by the model.

The estimated models below have been obtained using iterative generalised least squares (IGLS) estimation with first order marginal quasi-likelihood (MQL) approximation via the software package MLwiN 2.0 (Rasbash, Steele, Browne, \& Prosser, 2004).

\section{PSYCHIATRIC MORBIDITY AND SOCIAL CAPITAL}

The results of preliminary investigations on the relationship between mental health and each social capital variable are given in Table 2. The middle three columns of Table 2 present simple bivariate associations between each social capital aspect and psychiatric morbidity. These are statistically tested via corresponding Pearson's $\chi^{2}$ values at appropriate degrees of freedom along with their level of significance (p-value) 
in parentheses and an indication of achieving the $0.10(*)$ or $0.05(* *)$ commonly used pvalue thresholds (see $4^{\text {th }}$ column of Table 2). The second column gives the percentage of respondents who reported psychiatric morbidity and the respective social capital characteristic. For instance, $8.3 \%$ of respondents reported psychiatric morbidity and high social cohesion while 5.9\% have high CIS-R scores and low social cohesion (see fourth and fifth rows in the second column of Table 2). This does not agree with the theoretical suggestion that poor mental health is associated with low social cohesion and, indeed, the association is not significant as indicated by the low value of the respective Pearson $\chi^{2}$ statistic with one degree of freedom $\left(0.42\right.$, first figure in the $4^{\text {th }}$ column of Table 2$)$.

$<$ Insert Table 2 about here>

Psychiatric morbidity is significantly associated with perceived differences in political party preference and landholdings, number of perceived differences, perceived solidarity, social networks and support (see $4^{\text {th }}$ column of Table 2 ). More people have high psychiatric morbidity and perceive political party preference differences than not (8.3\% and 5.9\%, respectively) contrasting the relative group membership in the general population. Indeed, less people perceive these differences than not $(45.3 \%$ and $54.7 \%$, respectively). The odds of perceiving landholdings differences are significantly higher in conjunction with psychiatric morbidity $(5.0 / 9.2=0.54)$ than generally $(24.3 / 75.7=$ 0.32). The mean number of perceived differences is significantly higher for people with psychiatric morbidity (2.2) than without (1.6) according to ANOVA F-test (5.5) with 1 and 422 degrees of freedom.

Just over nine percent $(9.2 \%)$ of respondents do not perceive solidarity in their communities and are psychiatrically morbid against a $5.0 \%$ who reported both solidarity 
and high CIS-R. This difference is disproportionate compared to the general population which is roughly equally divided between those who do (46.5\%) and those who do not perceive solidarity (53.5\%). Respondents with psychiatric morbidity also reported fewer (than four) friends and less social support, i.e., less than 4 people to borrow money from, than those with good mental health.

Social capital may be related to partly similar demographic and socio-economic characteristics as psychiatric morbidity. It may thus be endogenous in the later estimated models. Preliminary multilevel logit regressions of psychiatric morbidity, whereby alternative social capital instruments are the only explanatory variable, have been fitted to investigate their respective unconditional effects. The estimated fixed parameters (together with standard errors and an indication of their statistical significance) of each social capital construct on psychiatric morbidity are presented in the last column of Table 2.

Perceived political party preference and landholdings divisions, as well as the number of perceived differences significantly increase the odds of psychiatric morbidity by $77 \%$ (calculated as $[\exp (0.57)-1] \times 100), 95 \%$ (calculated as $[\exp (0.67)-1] \times 100)$, and $16 \%$ for each additional perceived difference, respectively. Perceived solidarity is marginally associated with lack of psychiatric morbidity. Social networks and support of four or more friends significantly reduce the odds of psychiatric morbidity by $81 \%$ and $63 \%$, respectively. All other social capital aspects however seem unrelated to psychiatric morbidity.

\section{RESULTS}




\section{Modelling strategy}

Table 3 gives summary statistics and Table 4 the parameters of the empirical models of the association between psychiatric morbidity and social capital accounting for other individual and community characteristics and the clustering of individuals within communities.

The baseline or empty model, whereby only a random intercept at the individual and community levels is fitted, is given as a benchmark and disentangles the (unexplained) variation of psychiatric morbidity within and between communities. Apart from a baseline, four models are presented. The first model includes only individual demographic and socio-economic characteristics (Model 1). All demographic and socioeconomic characteristics of Table 2 entered preliminary versions of Model 1 but apart from sex, age and employment, which are theoretically pivotal for our research questions, only statistically significant predictors have been retained.

Model 2 expands Model 1 via adding individuals' social capital indicators. All social capital indicators which have been discussed in Section 3 entered incrementally a preliminary Model 2 but again only the statistically significant ones have been retained. Social networks and support which are highly associated entered alternative models. For the same reason perceived divisions in landholdings or political party preference and their number were separately regressed. The results shown in Tables 3 and 4 employ the number of perceived differences. The models which use perceived political party or landholdings differences instead are strikingly similar to the ones presented here. All results not shown here are available from the authors. 
Community attributes have been incrementally added to Model 2 to give Models 3 and 4. Any level - 2 characteristics with statistically significant coefficients have been kept in the model even if their significance became eventually marginal. Property crime seems to encompass all community level variability (Model 3).

The estimated random, $\hat{\sigma}_{e}^{2}, \hat{\sigma}_{u 0}^{2}$, and fixed parameters, $\hat{\beta}_{p}, p=0,1,2, \ldots, P$, of respondents' socio-demographic characteristics, social capital and their community profile over psychiatric morbidity are given in Table 4 . Their respective standard errors and an indication of statistical significance are also shown. The latter is based on Wald tests, which are $\chi^{2}$ distributed with one degree of freedom. Deviance statistics test the join significance of each set of explanatory variables, i.e., individual and community. They are multi-parameter Wald tests which follow the $\chi^{2}$ theoretical distribution with the appropriate degrees of freedom (Greene 1997) and an indication of their statistical significance is provided.

How much mental health is explained between and within communities?

The summary statistics of Table 3 refer to models with increasing complexity as described in the previous section. The (residual) intra-community correlation (ICC, see equation 2) is given in the second column of Table 3 while the next one gives the respective proportion of explained variance by each estimated model, $R_{\text {dicho }}^{2}$ (see equation $3)$. 
Two points should be made with respect to $R_{\text {dicho }}^{2}$ : First, as mentioned, the proportion of explained variance, $\boldsymbol{R}_{\text {dicho }}^{2}$, depends on the characteristics included in the linear predictor which bases its calculation. The attributes selected to calculate the linear predictor and $\boldsymbol{R}_{\text {dicho }}^{2}$ of psychiatric morbidity are such that their coincidence is plausible. They are given as notations below Table 3. All individual demographic and socioeconomic characteristics, except employment, and population size refer to the sample's mode. Housewife has been used for employment status as it makes the fictitious female who bases our predictions more tangible. Social capital and the remaining community characteristics which are included in the respective Models 2 to 4 have been assumed in calculating the model's explained variance, $\boldsymbol{R}_{\text {dicho }}^{2}$, in order to take full advantage of significant predictors. The explained variance for any plausible combination of characteristics can be calculated via similar simulations.

The second point that merits some attention is that in general $\mathrm{R}^{2}$ values for nonlinear outcomes, such as from multilevel logit models, are 'considerably lower than the OLS R ${ }^{2}$ values obtained for predicting continuous outcomes' (Snijders and Bosker 1999, page 226). In light of this the individual and community characteristics of this work explain surprisingly well psychiatric morbidity $(0.32)$.

The last two columns disentangle the proportion of total unexplained variance (1$R_{\text {dicho }}^{2}$ ) between the two sources of variation, i.e., between communities and between individuals $\left(\hat{\sigma_{u 0}^{2}}\right.$ and $3.29 \hat{\sigma_{e}^{2}}$, respectively). The within communities unexplained variability of psychiatric morbidity drops due to accounting for individual characteristics. The between communities unexplained variability is eliminated and essentially fully 
attributed to the model's community predictors of psychiatric morbidity (see Models 3 and 4).

The previous observations are reflected in the respective ICC values which, as mentioned, imply persistent between communities variability. Considering other social sciences results, for instance, in education, the ICC for psychiatric morbidity is surprisingly high, i.e., 0.27 (for the baseline model). It implies that the psychiatric morbidity of two randomly selected individuals from a randomly selected community is correlated by 0.3 . Individual characteristics and social capital reduce the residual ICC while community characteristics seem to fully account for any persistent unexplained heterogeneity of psychiatric morbidity between communities (see also the last row in the fourth and fifth column of the later Table 4). To sum up, individual and community attributes explain a significant portion (about 30\%) of the variance of psychiatric morbidity and all remaining unexplained heterogeneity (64\%) is essentially between individuals. Thus additional individual rather than community factors which are unmeasured here, such as family history, or generally unobserved may shed more light on poor mental health.

$<$ Insert Table 3 about here>

\section{Predictors of psychiatric morbidity}

Table 4 presents the results of psychiatric morbidity over individual demographic, socio-economic and social capital measurements as well as community characteristics. Age, employment, nationality, number of children or adults in the household, home ownership, length of residence in the area, number of cars or pick up trucks, most social 
capital indicators (see also earlier preliminary associations) and community characteristics are unrelated to psychiatric morbidity.

Men have at most half the odds of psychiatric morbidity than women $(51 \%$ reduction, calculated as $[\exp (-0.71)-1] \times 100$ from Model 1). By contrast, people with primary and secondary education have at least four (calculated as [exp(1.63)-1] from Model 1) and three (calculated as $[\exp (1.42)-1]$ from Model 1) times higher odds of psychiatric morbidity than those with higher education, respectively. Primary education is confined with age as older people tend to have lower qualifications. Indeed the mean age of respondents with just elementary schooling is 50.6 years old while that of people with secondary and higher education degree is 37 and 40 years old, respectively. Having said that however a model omitting education did not improve the statistical significance of age. People from medium income households (10,000-20,000 euros) have roughly $62 \%$ (calculated as $[\exp (-0.97)-1] \times 100$ from Model 1) lower odds of psychiatric morbidity than those with high income (more than 20,000 euros).

Perceived solidarity and surprisingly 'no friends to borrow from' are marginally associated with a lower odds of psychiatric morbidity by $42 \%$ and $45 \%$ (calculated as $[\exp (-0.54)-1] \times 100$ and $[\exp (-0.59)-1] \times 100$ from Model 2, respectively). The latter however should be interpreted with caution, especially since the unconditional association showed that having four or more friends to borrow from predicts a significant reduction of psychiatric morbidity by $63 \%$ while no social support had a negative but non- significant parameter (see Table 2). One possible explanation is that social support is highly associated with the socio- demographic characteristics which are included in the 
final models, especially age and educational and income levels. This issue is revisited in the next and final section.

Each additional perceived difference between community members significantly increases the odds of psychiatric morbidity by roughly $20 \%$. Similarly, perceived divisions with regards to political party preference and landholdings continue to significantly raise the likelihood of psychiatric morbidity when other individual and community attributes are accounted for. Property crime or youth clubs in the community as reported by the community representative are associated with lower odds of psychiatric morbidity (60\% and 66\%, see respective Models 3 and 4, Table 4) while living in a small community (100 to 249 residents) increases these odds by $99 \%$ with marginal statistical significance (see Model 4, Table 4).

< Insert Table 4 about here>

All individual characteristics which are included in Table 4 are jointly important predictors of psychiatric morbidity while property crime is more so than population size and youth clubs together (see respective Deviance statistics). The estimated extra -

binomial variation of psychiatric morbidity, $\hat{\sigma_{e}^{2}}$, confirms that its distribution is well approximated by the logit specification. The between communities variation is fully accounted for by the community characteristics in Models 3 and 4 of Table 4 .

\section{DISCUSSION}

To our knowledge, this is the first study on social capital and mental health that employs a fully structured, well-validated clinical interview (CIS-R) as a mental health outcome within a rural setting. A large number of rural communities $(n=89)$ was examined from 
five islands ensuring variation in scores between individuals and communities. Sampling all the small rural settlements of a whole region for data collection and conducting a detailed psychiatric interview were strengths of this study. Another contribution is the use of standard definitions of social capital in conjunction with measures of its different aspects, including social participation, trust, social cohesion, beliefs of collective efficacy and sense of belonging. This study disentangles the individual and community influences on psychiatric morbidity through multilevel modelling. Psychiatric morbidity is to a large extent clustered within rural communities.

The present findings succeeded in providing evidence about the role that some aspects of social capital may play in mental health. Perceived divisions between community members with regards to political party preference and landholdings significantly raise the likelihood of psychiatric morbidity even when other individual and community attributes are accounted for. Each additional perceived difference between community members significantly increases the odds of psychiatric morbidity by roughly $20 \%$. Perceived differences with regards to political party preferences may reflect differentiated access to power resources, both material and symbolic. Social anthropological research has revealed that political preferences constitute an indication of how rural people relate to central administration and decision making structures (Papataxiarchis, 1991). The way rural people relate to central authorities is indicative of how social positions are constructed within the specific socio-cultural context. This suggests that some community members are more privileged than others highlighting the need to examine issues of social position and roles in these small communities. The findings support the 'psycho-social' theoretical perspective in the area of health 
inequalities which argues that perceptions of relative deprivation or low social status engenders psychological distress, as expressed in feelings of low self-esteem, which effect the breakdown of social cohesion (Wilkinson, 1996).

Social cohesion is conceptualized as the degree of trust, sense of familiarity, shared values and bonding relations between individuals within a community (Carpiano, 2006). A critique however on the notion of social cohesion as an umbrella term that covers a range of social processes seems to gain some support by our results. Indeed, it was expected that strong perceptions of trust and social cohesion would correlate inversely with psychiatric morbidity. This research however shows that trust and social cohesion are unrelated to mental health unlike previous evidence of significant associations between trust, social cohesion and GHQ scores in urban settings (Araya, Dunstan, Playle, Thomas, Palmer \& Lewis, 2006). The lack of association may be due to the scale's inability to capture enough complexity or meaning in rural communities. Another interpretation is that close-knit networks, generalised trust and shared values do not seem to integrate status differences. It is also speculated that strong ties through kinship networks within these communities may signal heavy obligations. Therefore, social cohesion appears to be a multi - facet phenomenon that deserves further research.

Social capital in this study measured structural aspects by asking respondents to indicate participation of household members in voluntary or local organizations, extent of help received from friends for various needs, e.g. borrow money, and willingness among neighbours to help in hypothetical situations. The item concerning group membership was found to have no meaning to our respondents. Within the study's cultural setting, group membership is more implicit and informal in nature. It is clear that group practices 
of Greek villages vary from those described by Putnam (1993) and therefore the current study failed to reveal associations between structural social capital and mental health when other factors are accounted for due to cultural factors: borrowing money may seem degrading and lack its original theoretical meaning. The evidence that wider social support (four or more friends to borrow from) unconditionally reduces psychiatric morbidity risk suggests that its role may be conditioned by socio-demographic characteristics (McKenzie \& Harpham, 2006).

Questions about perceived solidarity and collective efficacy consider community members' beliefs in their ability to act collectively to address a common issue. These beliefs were indicated by whether the majority of the rural community's residents would join forces to address a common disaster, would be involved in organizing a festival or a fair in the village and would be willing to invest both money and time. The present research found that perceived solidarity is associated with lower odds of psychiatric morbidity albeit at marginal statistical significance. This suggests that feelings of community competence can have many positive effects on mental health such as a sense of security, perceptions of control and hope (McCulloch, 2003).

Sense of belonging is arguably an important dimension of social capital and a number of theoreticians propose that it is the glue that holds communities together (Sarason, 1974). The current study however did not evidence any relationship with mental health. Our study is limited in that only two items were used to capture this dimension.

Community attributes play a significant role to levels of psychiatric morbidity. The unexpected negative association between property crime and psychiatric morbidity 
implies that property crime may foster sense of community. A number of researchers have suggested that there is a curvilinear relationship between local problems and sense of community (Anderson \& Milligan, 2006). A moderate degree of fear of crime may serve as a catalyst for the members of a community to come together to work on resolving threats (Chavis \& Wandersman, 1990).

To sum up, the results offer powerful evidence that perceived social distinctions in a rural context may damage individuals' psychological well-being. The internal dynamics however between psychological processes which link perceived social divisions, social statues and psychiatric morbidity are not fully understood. This study reinforces the need for measures of social capital that capture the complexity of the concept and empirical analyses that model mental health and social capital jointly. 


\section{REFERENCES}

Anderson, A.A. \& Milligan, S. (2006). Social capital and community building. In K. Fulbright-Anderson \& P. Auspos (Eds.) Community Change: Theories, Practice \& Evidence (pp. 21-60). Maryland: The Aspen Institute.

Araya, R., Rojas G., Fritsch R., Acuña, J. \& Lewis, G. (2001). Common mental disorders in Santiago, Chile. Prevalence and socio-demographic correlates. British Journal of Psychiatry, 178, 228-233.

Araya, R., Dunstan, F., Playle, R., Thomas, H., Palmer, S. \& Lewis, G. (2006). Perceptions of social capital and the built environment and mental health. Social Science \& Medicine, 62, 3072-3083.

Berkman, L.F., Glass, Th., Brissette, I., Seeman, T.E. (2000). From social integration to health: Durkheim in the new millennium. Social Science \& Medicine, 51, 843-857.

Chavis, D.M. \& Wandersman, A. (1990). Sense of community in the urban environment: A catalyst for participation and community development. American Journal of Community Psychology, 18, 55-81.

De Silva, M (2006). Systematic review of the methods used in studies of social capital and mental health. In K. McKenzie \& T. Harpham (Eds.) Social Capital and Mental Health (pp. 39-67). London: Jessica Kingsley Publishers.

Forbes, A., \& Wainwright, S. P. (2001). On the methodological, theoretical and philosophical context of health inequalities research: A critique. Social Science and Medicine, 53, 801-816. 
Grootaert, C., \& vanBastelaer, T. (Eds.) (2002). Understanding and Measuring Social Capital. Washington: The World Bank.

Goldstein, H. (1995). Multilevel Statistical Models (2 ${ }^{\text {nd }}$ ed.). London: Arnold.

Greene, W. H. (1997). Econometric Analysis. Upper Saddle River, NJ: Prentice Hall.

Jenkins R, Bebbington P, Brugha T, Farrell M, Gill B, Lewis G, Meltzer H, Petticrew M (1997). The National Psychiatric Morbidity Surveys of Great Britain: strategy and methods. Psychological Medicine, 27, 765-774.

Kalton, G. (1983). Introduction to survey sampling Series Quantitative Applications in the Social Sciences A Sage University Paper 35 Newbury Park: Sage.

Landis, J.R., \& Koch, G.G. (1977). The measurement of observer agreement for categorical data. Biometrics, 33, 159-174.

Lochner, K., Kawachi, I., \& Kennedy, B. P. (1999). Social capital: A guide to its measurement. Health and Place, 5, 259-270.

Lewis, G., Pelosi, J., Araya, R., Dunn, G. (1992). Measuring psychiatric disorder in the community: A standardized assessment for use by lay interviewers. Psychological Medicine, 22, 465-486.

McCulloch, A. (2001). Social environments and health: cross-sectional national survey. British Medical Journal, 323, 208-209.

McKeehan, I.V. (2000) A multilevel city health profile of Moscow. Social Science and Medicine, 51 1295-1312. 
McKenzie, K. \& Harpham, T. (2006). Meanings and uses of social capital in the mental health field. In K. McKenzie \& T. Harpham (Eds.) Social Capital and Mental Health (pp. 11-23). London: Jessica Kingsley Publishers.

Papataxiarchis, E. (1991). Friends of the heart: Male commensal solidarity, gender and kinship in Aegean Greece. In P. Loizos \& E. Papataxiarchis (Eds.), Contested Identities: Gender and Kinship in Modern Greece. Princeton: Princeton University Press.

Putnam, R. (1993). The prosperous community: Social capital and public life. American Prospect, 13, 35- 42.

Rasbash, J., Steele, F., Browne, W. \& Prosser, B. (2004). A User's Guide to MLwiN. Version 2.0. London: Institute of Education.

Sampson, R. J., Raundenbush, S.W., \& Earls, F. (1997). Neighbourhoods and violent crime: A multilevel study of collective efficacy. Science, 227, 918-924.

Sanne, B., Mykletun, A., Moen, B. E., Dahl, A. A., \& Tell, G. S. (2004). Farmers are at risk for anxiety and depression: The Hordaland health study. Occupational Medicine, 54, 92-100.

Sarason, S.B. (1974). The psychological sense of community: Perspectives for community psychology. San Francisco: Jossey-Bass.

Snijders, T.A.B., \& Bosker R.J. (1999). Multilevel Analysis: An Introduction to Basic and Advanced Multilevel Modeling. London: SAGE. 
Whitley, R., \& Prince, M. (2005). Is there a link between rates of common mental disorder and deficits in social capital in Gospel Oak, London? Results from a qualitative study. Health \& Place, 11, 237-248.

Wilkinson, R. (1996). Unhealthy societies. The affliction of inequality. London: Routledge

Woolcock, M. \& Narayan, D. (2000). Social capital: Implications for development theory, research, and policy. The World Bank Research Observer, 15, 225-249.

Zissi, A., Tseloni, A., Skapinakis, P., Savvidou, M., \& Chiou, V. (2010). Exploring social capital in rural settlements of an islander region in Greece. Journal of Community \& Applied Social Psychology, 20, 125-138. 
Table 1: Description of variables

\begin{tabular}{|c|c|c|c|}
\hline & $\%$ & $\begin{array}{c}\text { Mean } \\
\text { (Min, Max) }\end{array}$ & $\begin{array}{c}\text { Standard } \\
\text { Deviation }\end{array}$ \\
\hline \multicolumn{4}{|c|}{ Individual level $(\mathrm{N}=424)$} \\
\hline \multicolumn{4}{|c|}{ Mental health } \\
\hline Mental Health Index & & $4.5(1,6)$ & 1.0 \\
\hline Poor mental health $(\mathrm{MHI} \leq 3.20)$ & 13.2 & & \\
\hline CIS-R & & $5.70(1,27)$ & 5.73 \\
\hline Psychiatric morbidity (CIS-R $\geq 12$ ) & 14.2 & & \\
\hline \multicolumn{4}{|c|}{ Social Capital } \\
\hline Social cohesion index & & $2.7(1,5)$ & 0.9 \\
\hline Low social cohesion $($ Index $<2.6$ ) & 45.5 & & \\
\hline \multicolumn{4}{|l|}{ Perceived differences } \\
\hline Total number & & $1.7(0,9)$ & 1.90 \\
\hline In political party preference & 45.3 & & \\
\hline In landholdings & 24.3 & & \\
\hline In mentality & 21.7 & & \\
\hline Institutional trust & 52.6 & & \\
\hline Perceived solidarity & 46.5 & & \\
\hline Collective mobilization & 45.0 & & \\
\hline Willingness to invest & 62.3 & & \\
\hline Attachment & 50.9 & & \\
\hline \multicolumn{4}{|l|}{ Number of close friends } \\
\hline None & 34.9 & & \\
\hline One to three & 49.5 & & \\
\hline Four or more & 15.6 & & \\
\hline \multicolumn{4}{|l|}{ Number of friends to ask for money } \\
\hline None & 34.9 & & \\
\hline One to three & 44.8 & & \\
\hline Four or more & 20.3 & & \\
\hline \multicolumn{4}{|c|}{ Individual and household characteristics } \\
\hline Male & 47.9 & & \\
\hline Age & & $43.3(18,76)$ & 13.6 \\
\hline Non Greek & 0.9 & & \\
\hline \multicolumn{4}{|l|}{ Employment status } \\
\hline Farmer & 28.3 & & \\
\hline Housewife & 22.4 & & \\
\hline Employee & 20.3 & & \\
\hline Small business & 15.3 & & \\
\hline Pensioner & 7.5 & & \\
\hline Other (unemployed or university student) & 6.2 & & \\
\hline \multicolumn{4}{|l|}{ Educational level } \\
\hline Preliminary or lower & 44.3 & & \\
\hline Secondary & 46.9 & & \\
\hline Tertiary & 8.7 & & \\
\hline
\end{tabular}


Table 1: Description of variables (continued)

\begin{tabular}{|c|c|c|c|}
\hline & $\%$ & $\begin{array}{c}\text { Mean } \\
(\text { Min, Max })\end{array}$ & $\begin{array}{c}\text { Standard } \\
\text { Deviation } \\
\end{array}$ \\
\hline \multicolumn{4}{|c|}{ Individual level $(\mathrm{N}=424)$} \\
\hline \multicolumn{4}{|c|}{ Individual and household characteristics } \\
\hline \multicolumn{4}{|l|}{ Number of children } \\
\hline None & 60.8 & & \\
\hline One & 18.2 & & \\
\hline Two or more & 21.0 & & \\
\hline \multicolumn{4}{|l|}{ Number of adults } \\
\hline One & 4.5 & & \\
\hline Two & 53.0 & & \\
\hline Three or more & 42.5 & & \\
\hline Home owners & 91.7 & & \\
\hline Length of residence & & $22.4(1,65)$ & 14.8 \\
\hline \multicolumn{4}{|l|}{ Household income } \\
\hline Less than 10,000 euros & 40.6 & & \\
\hline $10,000-20,000$ euros & 43.4 & & \\
\hline Over 20,000 euros & 14.4 & & \\
\hline Refused to answer & 1.7 & & \\
\hline \multicolumn{4}{|l|}{ Number of cars } \\
\hline None & 33.5 & & \\
\hline One & 54.2 & & \\
\hline Two or more & 12.3 & & \\
\hline \multicolumn{4}{|l|}{ Number of trucks } \\
\hline None & 38.0 & & \\
\hline One & 57.8 & & \\
\hline Two & 3.8 & & \\
\hline \multicolumn{4}{|c|}{ Community level $(\mathrm{N}=89)$} \\
\hline \multicolumn{4}{|l|}{ Population Size } \\
\hline Less than 99 residents & 32.6 & & \\
\hline $100-249$ residents & 34.8 & & \\
\hline Over 250 residents & 32.6 & & \\
\hline Primary school & 55.1 & & \\
\hline Nursery & 49.4 & & \\
\hline Improved employment & 27.0 & & \\
\hline Stable employment & 47.2 & & \\
\hline Good quality of life & 59.6 & & \\
\hline Trust & 58.4 & & \\
\hline $\begin{array}{l}\text { Perceived higher trust than other } \\
\text { communities }\end{array}$ & 19.1 & & \\
\hline Interest in community's well-being & 29.2 & & \\
\hline Some internet access & 57.3 & & \\
\hline Public market space & 66.3 & & \\
\hline
\end{tabular}


Table 1: Description of variables (continued)

\begin{tabular}{|c|c|c|c|}
\hline & $\%$ & $\begin{array}{c}\text { Mean } \\
(\text { Min, Max) }\end{array}$ & $\begin{array}{c}\text { Standard } \\
\text { Deviation }\end{array}$ \\
\hline \multicolumn{4}{|c|}{ Community level $(\mathrm{N}=89)$} \\
\hline Recreation areas & 58.4 & & \\
\hline Cooperatives & 80.9 & & \\
\hline Parents teachers associations & 42.7 & & \\
\hline Youth organisations /clubs & 12.4 & & \\
\hline Sport clubs & 42.7 & & \\
\hline Culture clubs & 71.9 & & \\
\hline Common action to tackle a problem & 31.5 & & \\
\hline Property crime & 16.9 & & \\
\hline Alcohol abuse & 21.3 & & \\
\hline Drug abuse & 14.6 & & \\
\hline
\end{tabular}


Table 2: Bivariate associations between psychiatric morbidity and each indicator of social capital

\begin{tabular}{|c|c|c|c|c|}
\hline & \multicolumn{3}{|c|}{ Contingency Tables } & Multilevel Logit \\
\hline \multicolumn{3}{|c|}{ Percentage of Respondents } & \multirow{2}{*}{$\begin{array}{c}\text { Pearson } \chi_{1}^{2} \\
(\mathrm{p} \text {-value })\end{array}$} & \multirow{2}{*}{$\begin{array}{c}\hat{\beta}_{p} \\
\text { (Standard Error) }\end{array}$} \\
\hline With Psychiatric Morbidity and the fol & wing: & Total & & \\
\hline Low Social Cohesion & 5.9 & 45.5 & & $0.21(0.15)$ \\
\hline High Social Cohesion & 8.3 & 54.5 & $0.418(0.52)$ & \\
\hline $\begin{array}{l}\text { Perceived differences in political party } \\
\text { preference }\end{array}$ & 8.3 & 45.3 & & $0.57^{* *}(0.28)$ \\
\hline None or Other & 5.9 & 54.7 & $4.80^{* *}(0.03)$ & \\
\hline Perceived differences in landholdings & 5.0 & 24.3 & & $0.67^{* *}(0.29)$ \\
\hline None or Other & 9.2 & 75.7 & $4.36^{* *}(0.04)$ & \\
\hline Perceived differences in mentality & 3.1 & 21.7 & & $0.03(0.32)$ \\
\hline None or Other & 11.1 & 78.3 & $0.00(0.99)$ & \\
\hline Institutional trust & 7.3 & 52.6 & & $0.05(0.26)$ \\
\hline None & 6.8 & 47.4 & $0.02(0.88)$ & \\
\hline Perceived solidarity & 5.0 & 46.5 & & $-0.50^{*}(0.28)$ \\
\hline None & 9.2 & 53.5 & $3.69^{*}(0.06)$ & \\
\hline Collective mobilisation & 5.9 & 45.0 & & $-0.25(0.28)$ \\
\hline None & 8.3 & 55.0 & $0.32(0.57)$ & \\
\hline Willingness to invest & 9.7 & 62.3 & & $0.36(0.28)$ \\
\hline None & 4.5 & 37.7 & $1.10(0.30)$ & \\
\hline Attachment & 5.9 & 50.9 & & $-0.42(0.27)$ \\
\hline \multirow[t]{2}{*}{ Lack of attachment } & 8.3 & 49.1 & $2.41(0.12)$ & \\
\hline & & & Pearson $\chi_{2}^{2}$ & \\
\hline No close friends & 5.7 & 3.9 & & $0.06(0.28)$ \\
\hline One to three close friends & 8.0 & 49.5 & & 1 \\
\hline Four or more close friends & 0.5 & 15.6 & $7.96^{* *}(0.02)$ & $-1.66^{* * *}(0.64)$ \\
\hline No friends to borrow money from & 5.0 & 34.9 & & $-0.18(0.28)$ \\
\hline One to three friends to borrow money from & 7.8 & 44.8 & & 1 \\
\hline Four or more friends to borrow money from & 1.4 & 20.3 & $5.26^{*}(0.07)$ & $-1.00^{* *}(0.43)$ \\
\hline \multirow[t]{3}{*}{ Total } & 14.2 & $\mathrm{~N}=424$ & & \\
\hline & & ANOVA & & \\
\hline & $\begin{array}{l}\text { Psychiatric } \\
\text { Morbidity }\end{array}$ & $\begin{array}{c}\text { Lack of } \\
\text { Psychiatric } \\
\text { Morbidity }\end{array}$ & $\begin{array}{c}\text { F-test } 1,422 \\
\text { (p-value) }\end{array}$ & \\
\hline Number of perceived differences & Mean $=2.20$ & Mean $=1.58$ & $5.50^{* *}(0.02)$ & $0.15^{* * *}(0.07)$ \\
\hline
\end{tabular}

\footnotetext{
${ }^{*} 0.10>$ p-value $>0.05 ;{ }^{* *} 0.05>$ p-value $>0.01 ;{ }^{* * *} 0.01 \geq \mathrm{p}$-value.
} 
Table 3: Residual intra-class correlation and percentage of explained variability across models of psychiatric morbidity of individuals nested within communities.

\begin{tabular}{|c|c|c|c|c|}
\hline \multirow{3}{*}{$\begin{array}{l}\text { Estimated model (assumptions } \\
\text { about explanatory variables' } \\
\text { categories) }\end{array}$} & \multirow{3}{*}{$\begin{array}{l}\text { Residual } \\
\text { ICC }\end{array}$} & \multirow{3}{*}{$\begin{array}{l}\text { Explained } \\
\text { Variance }\end{array}$} & \multicolumn{2}{|c|}{ Unexplained Variance } \\
\hline & & & \multicolumn{2}{|c|}{ Between } \\
\hline & & & Communities & Individuals \\
\hline Baseline & 0.27 & 0.00 & 0.27 & 0.73 \\
\hline Model $1^{\mathrm{a}}$ & 0.17 & 0.16 & 0.14 & 0.70 \\
\hline Model $2^{b}$ & 0.16 & 0.24 & 0.12 & 0.64 \\
\hline Model $3^{c}$ & 0.11 & 0.30 & 0.07 & 0.63 \\
\hline Model $4^{\mathrm{d}}$ & 0.08 & 0.32 & 0.05 & 0.64 \\
\hline
\end{tabular}

${ }^{a}$ For a housewife with secondary education and household income 10,000-20,000 euros.

${ }^{\mathrm{b}}$ For the (a) individual who additionally reported 1-3 friends to borrow from, perceived solidarity and 1 perceived difference.

${ }^{\mathrm{c}}$ For the (b) individual who lives in a community where property crime was reported by the community representative.

${ }^{\mathrm{d}}$ For the (b) individual who lives in a community of 100-249 residents, with youth clubs, and where common action was reported. 
Table 4: Multilevel logit models of psychiatric morbidity over individual, household and community characteristics $(\mathrm{N}=424)$.

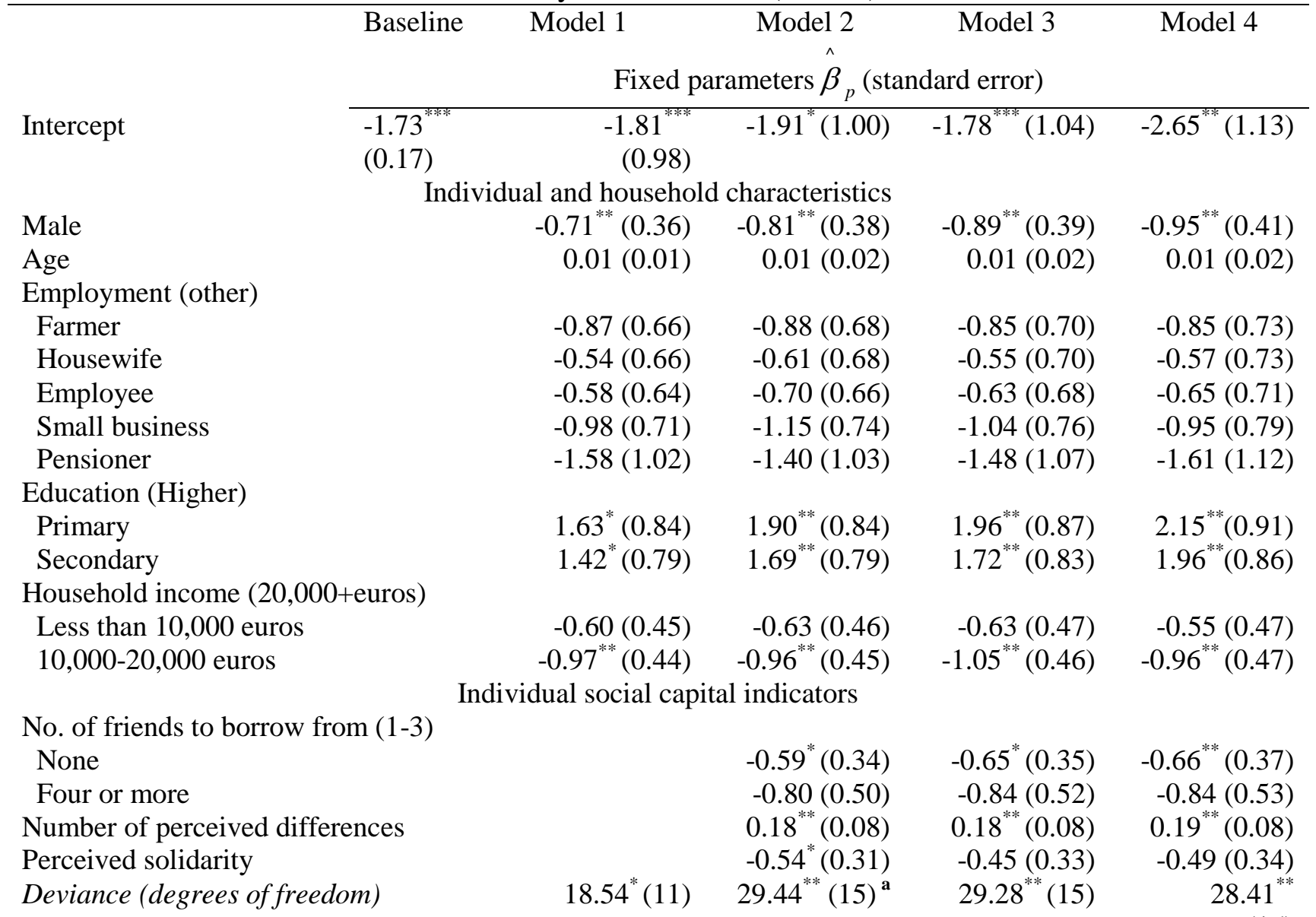

Community characteristics

Property crime

Population Size (over 250 residents)

Less than 99 residents

100-249 residents

Youth clubs in the community

$0.69^{*}(0.38)$

$-1.08^{*}(0.59)$

Common action to tackle a problem

Deviance (degrees of freedom)

$-0.93^{* *}(0.47)$

$0.41(0.40)$

$4.01^{* *}(1) \quad 6.64^{*}(4)$

Random parameters, $\hat{\sigma_{e}^{2}}$ and $\hat{\sigma_{u 0}^{2}}$

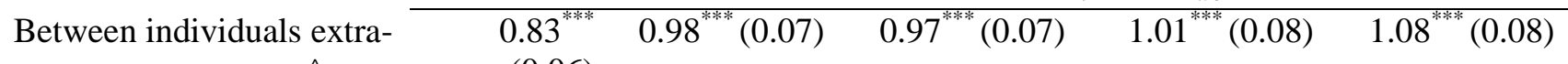
binomial variance $\left(\hat{\sigma_{e}^{2}}\right)$ (0.06)

Between communities variance $\left(\hat{\sigma_{u 0}^{2}}\right)$

$1.00^{* * *} \quad 0.64^{* * *}(0.37) \quad 0.61^{* *}(0.36) \quad 0.40(0.34) \quad 0.26(0.33)$

$(0.38)$

${ }^{*} 0.10>$ p-value $>0.05 ;{ }^{* *} 0.05>$ p-value $>0.01 ;{ }^{* * *} 0.01>$ p-value. One-tail tests for variance parameters. $2.71 \quad 3.84$

${ }^{a}$ Employment status does not effectively increase the explanatory power of the model. The Deviance of an estimated model without it is 28.36 with 10 degrees of freedom. 